\title{
What's new for ESC Congress 2013? (Amsterdam 30 August - 4 September 2013)
}

\author{
K. A. A. Fox
}

Published online: 19 April 2013

(C) The Author(s) 2013. This article is published with open access at Springerlink.com

\begin{abstract}
The innovative Spotlight of the Congress is "The heart interacting with systemic organs". For our patients, the interaction of cardiac conditions with other organs is fundamentally important to outcome, to safety and to clinical management. Related specialty areas have much to learn from each other and the ESC Congress 2013 will attract specialists from other organ systems to help understand disease mechanisms and improve the management of our patients.
\end{abstract}

\section{Keywords Heart}

The innovative Spotlight of the Congress is 'The heart interacting with systemic organs'. For our patients, the interaction of cardiac conditions with other organs is fundamentally important to outcome, to safety and to clinical management. Related speciality areas have much to learn from each other and the ESC Congress 2013 will attract specialists from other organ systems to help understand disease mechanisms and improve the management of our patients.

\section{A personalised and interactive congress}

At ESC Congress 2013 we can each develop a personalised curriculum, depending on speciality interests and training needs. This is a truly international meeting - the largest number of abstract submissions were from Japan! We have joint sessions with many societies around the world and 16 linked sessions and direct opportunities to interact with

K. A. A. Fox $(\bowtie)$

Centre for Cardiovascular Science, University of Edinburgh,

49 Little France Crescent, Edinburgh EH16 4SB, UK

e-mail: k.a.a.fox@ed.ac.uk experts and thought leaders. For the first time this year we have 'rapid fire' posters followed by interactive discussion around an electronic display featuring the key findings from each of the presented studies (Figs. 1, 2 and 3). Also for the first time, poster presentations will be stimulated by discussants who are experts in that field of investigation. Another innovation is 'Meet the Legends in Cardiology', where participants will be able to post questions in advance or during the session to individuals who have changed our understanding and helped determine the shape of cardiology in 2013 .

\section{'Villages' of linked topics}

There is huge and international enthusiasm for participation in the congress with a record number of submissions for scientific planned sessions (more than 400 were selected) and the second highest ever number of abstracts were submitted (10490). To make the congress more manageable we have again arranged the congress into 'villages' of related topics. Thus, a village may include presentations in one room on heart failure and

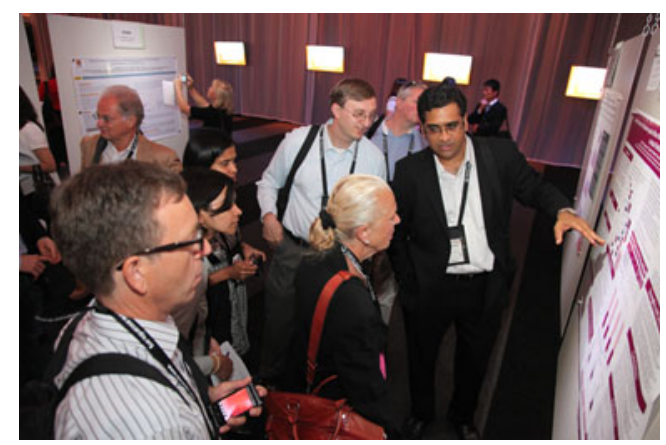

Fig. 1 (ESC 2351) Discussions around a poster at ESC Congress 


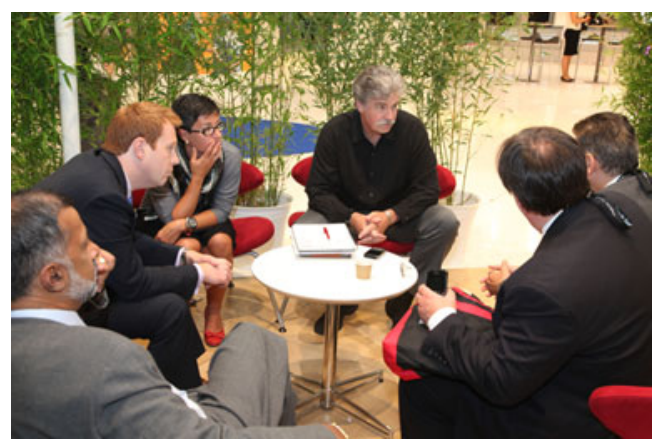

Fig. 2 (ESC 3704) Round table discussions at ESC

in an adjacent room on heart rhythm disturbances. Through the village concept the congress becomes more manageable and interactive. Important new guidelines will be presented at the ESC Congress 2013 on arterial hypertension, cardiac pacing, diabetes, and stable coronary artery disease. Linked to these will be dedicated scientific sessions, casebased Focus Sessions.

\section{Why should someone come and participate in the congress?}

Summaries of the Hotlines will appear online but to really understand the significance of the new research we need to discuss the findings with our colleagues. As National Society members we are all also members of the ESC! The ESC Congress provides the opportunity to decide what may influence understanding of innovations and practice at a national level. Editors of National Society Cardiovascular journals are

\section{ESC Congress 2013: the HUB}

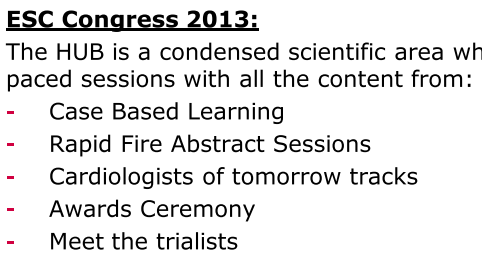

www.escardio.org

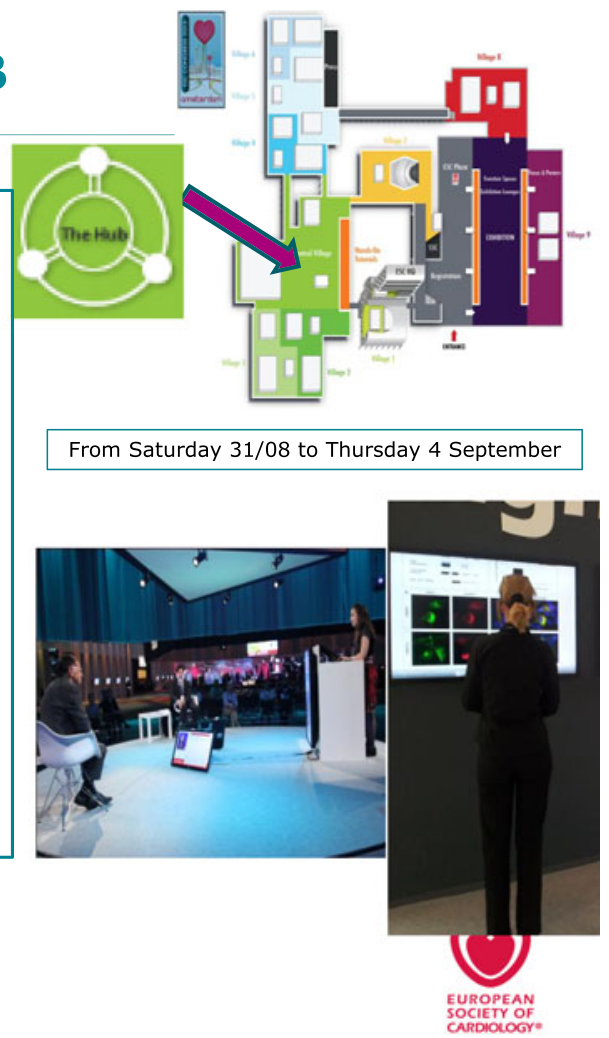

Fig. 3 Summary features of the ESC Congress 2013 Hub (ESC website) 
provided with the Hotline presentations and the Hotline extracts can be translated and printed in local cardiovascular journals.

The ESC Congress 2013 is the largest cardiovascular international congress and its true international nature provides exciting and innovative opportunities to discuss and interact with colleagues from all around the world. You have the choice: be part of the frontiers in cardiology and practice, or be an observer!

Open Access This article is distributed under the terms of the Creative Commons Attribution License which permits any use, distribution, and reproduction in any medium, provided the original author(s) and the source are credited. 